\title{
The Emerging Role of Radiomics in COPD and Lung Cancer
}

\author{
Turkey Refaee ${ }^{a, b}$ Guangyao Wu ${ }^{a}$ Abdallah Ibrahim ${ }^{a, c-e}$ Iva Halilaj ${ }^{a}$ \\ Ralph T.H. Leijenaar ${ }^{a}$ William Rogers ${ }^{a, g}$ Hester A. Gietema ${ }^{c}$ \\ Lizza E.L. Hendriks ${ }^{f}$ Philippe Lambin ${ }^{a, c}$ Henry C. Woodruffa, $c$
}

${ }^{a}$ The D-Lab, Department of Precision Medicine, GROW - School for Oncology and Developmental Biology, Maastricht University, Maastricht, The Netherlands; ${ }^{b}$ Department of Diagnostic Radiology, Faculty of Applied Medical Sciences, Jazan University, Jazan, Saudi Arabia; ' Department of Radiology and Nuclear Medicine, GROW - School for Oncology and Developmental Biology, Maastricht University Medical Centre+, Maastricht,

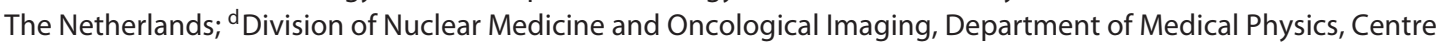
Hospitalier Universitaire de Liège, Liège, Belgium; ${ }^{e}$ Department of Nuclear Medicine and Comprehensive Diagnostic Center Aachen (CDCA), University Hospital RWTH Aachen University, Aachen, Germany; 'Department of Pulmonary Diseases, GROW - School for Oncology and Developmental Biology, Maastricht University, Maastricht, The Netherlands; ${ }^{9}$ Department of Thoracic Oncology, IRCCS Foundation National Cancer Institute, Milan, Italy

\section{Keywords}

Radiomics · Chronic obstructive pulmonary disease · Lung cancer

\begin{abstract}
Medical imaging plays a key role in evaluating and monitoring lung diseases such as chronic obstructive pulmonary disease (COPD) and lung cancer. The application of artificial intelligence in medical imaging has transformed medical images into mineable data, by extracting and correlating quantitative imaging features with patients' outcomes and tumor phenotype - a process termed radiomics. While this process has already been widely researched in lung oncology, the evaluation of COPD in this fashion remains in its infancy. Here we outline the main applications of radiomics in lung cancer and briefly review the workflow from image acquisition to the evaluation of model performance. Finally, we discuss the current assessments of COPD and the potential application of radiomics in COPD. @ 2020 The Author(s)

Published by S. Karger AG, Basel
\end{abstract}

\begin{tabular}{|c|c|}
\hline KARGER & $\begin{array}{l}\text { (C) } 2020 \text { The Author(s) } \\
\text { Published by S. Karger AG, Basel }\end{array}$ \\
\hline $\begin{array}{l}\text { E-Mail karger@karger.com } \\
\text { www.karger.com/res }\end{array}$ & $\begin{array}{l}\text { This is an Open Access article licensed under the Creative Commons } \\
\text { Attribution-NonCommercial-4.0 International License (CC BY-NC) } \\
\text { (http://www.karger.com/Services/OpenAccessLicense), applicable to } \\
\text { the online version of the article only. Usage and distribution for com- } \\
\text { mercial purposes reguires written permission. }\end{array}$ \\
\hline
\end{tabular}

\section{Introduction}

Chronic obstructive pulmonary disease (COPD) is one of the most prevalent lung diseases, with an estimated 328 million people worldwide being affected, and in two decades it is expected to become the leading cause of death globally [1]. COPD is characterized by the limitation of airflow, which can be measured using spirometry. It is not completely reversible and is often caused by exposure to noxious particles or gas (e.g., cigarette smoking) which creates an inflammatory response in the lung $[2,3]$. COPD is a multicomponent disease comprising a combination of bronchiolitis, emphysema, and extrapulmonary effects [4]. While spirometry can measure airflow limitation, the contributions of large and small airway involvement and the extent and contribution of parenchy-

From the Thematic Review Series: "Emerging Techniques in the World of Respiratory Imaging"

Series Editors: Lowie E.G.W. Vanfleteren and Dirk-Jan Slebos

Turkey Refaee

The D-Lab, Department of Precision Medicine

GROW - School for Oncology and Developmental Biology, Maastricht University

NL-6229 ER, Universiteitssingel 40, Maastricht (The Netherlands)

E-Mail t.refaee@maastrichtuniversity.nl 


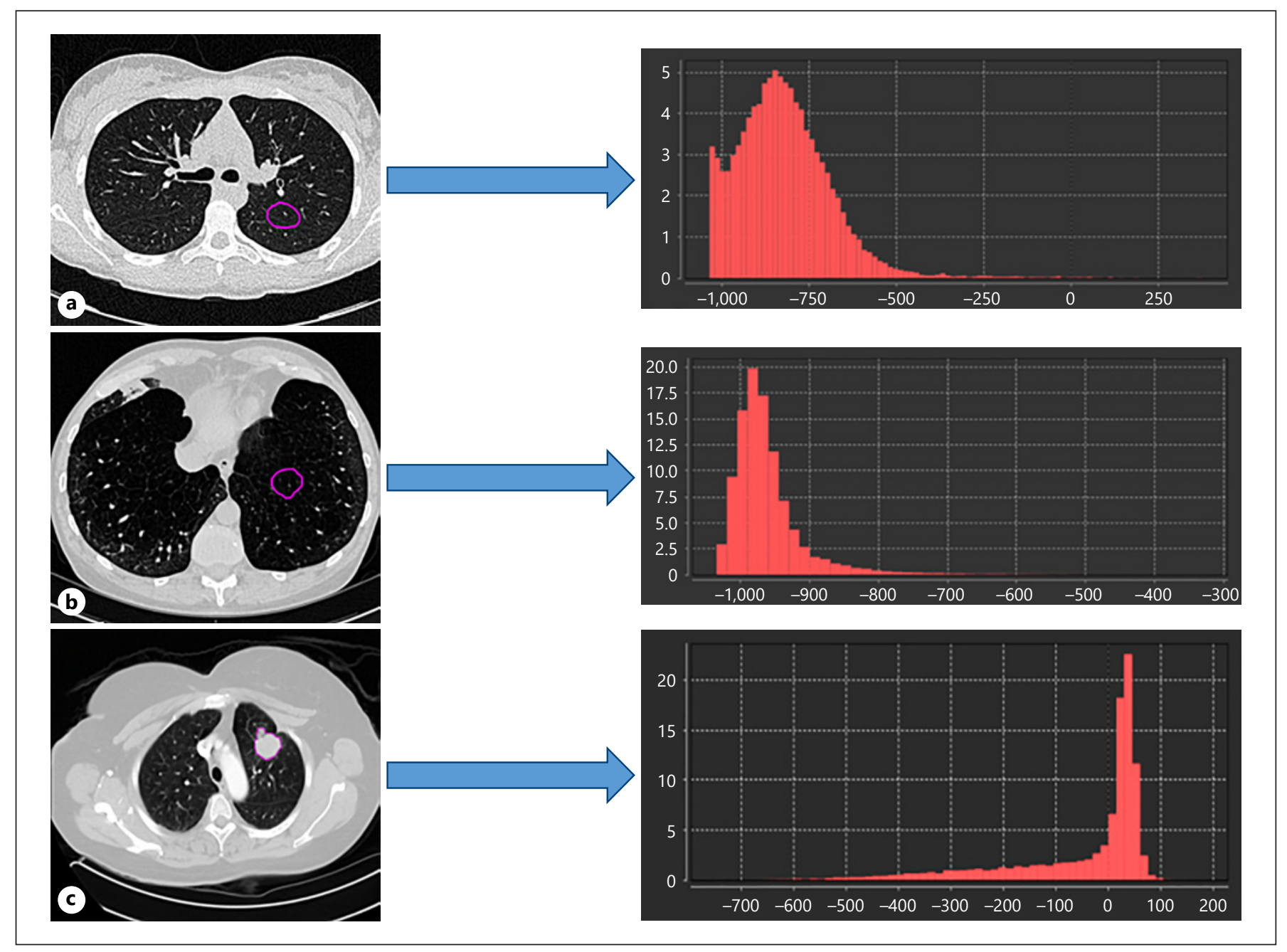

Fig. 1. Different distributions of HU values extracted from the ROI (purple outline) for normal tissue (a), COPD tissue (b), and lung tumor (c).

ma destruction cannot be assessed [5]. Imaging by means of computed tomography (CT) has an increasing role in the evaluation of COPD since CT features can suggest the presence and severity of COPD. These features can be assessed visually [6], but research is in advanced stages to automate the quantification of emphysema extent and distribution [7-10], airway wall thickness [11], and small airways disease [12].

Lung cancer is the other predominant lung disease, being one of the world's most prevalent cancers [13-16]. Globally, lung cancer is the most commonly diagnosed cancer (around $11 \%$ of all cancers in both sexes), and the world's leading cause of cancer-related mortality (around $18 \%$ of total cancer-related mortality) [17]. Lung cancers can be divided into two broad groups, small cell lung cancer and non-small cell lung cancer (NSCLC) [18]. NSCLC can be further divided into subgroups according to histopathology into squamous cell carcinoma and adenocarcinoma [19]. COPD has been shown to be a major additional risk factor for the development of lung cancer, specifically squamous cell carcinoma [20, 21]. Discovering the link between COPD and lung cancer has drawn significant attention in recent years [22]. It has been shown that COPD and lung cancer share similar pathological processes [23], while smoking cigarettes is one important common factor that causes both COPD and lung cancer [20], and patients with COPD and NSCLC have poor survival outcomes compared to NSCLC patients without 


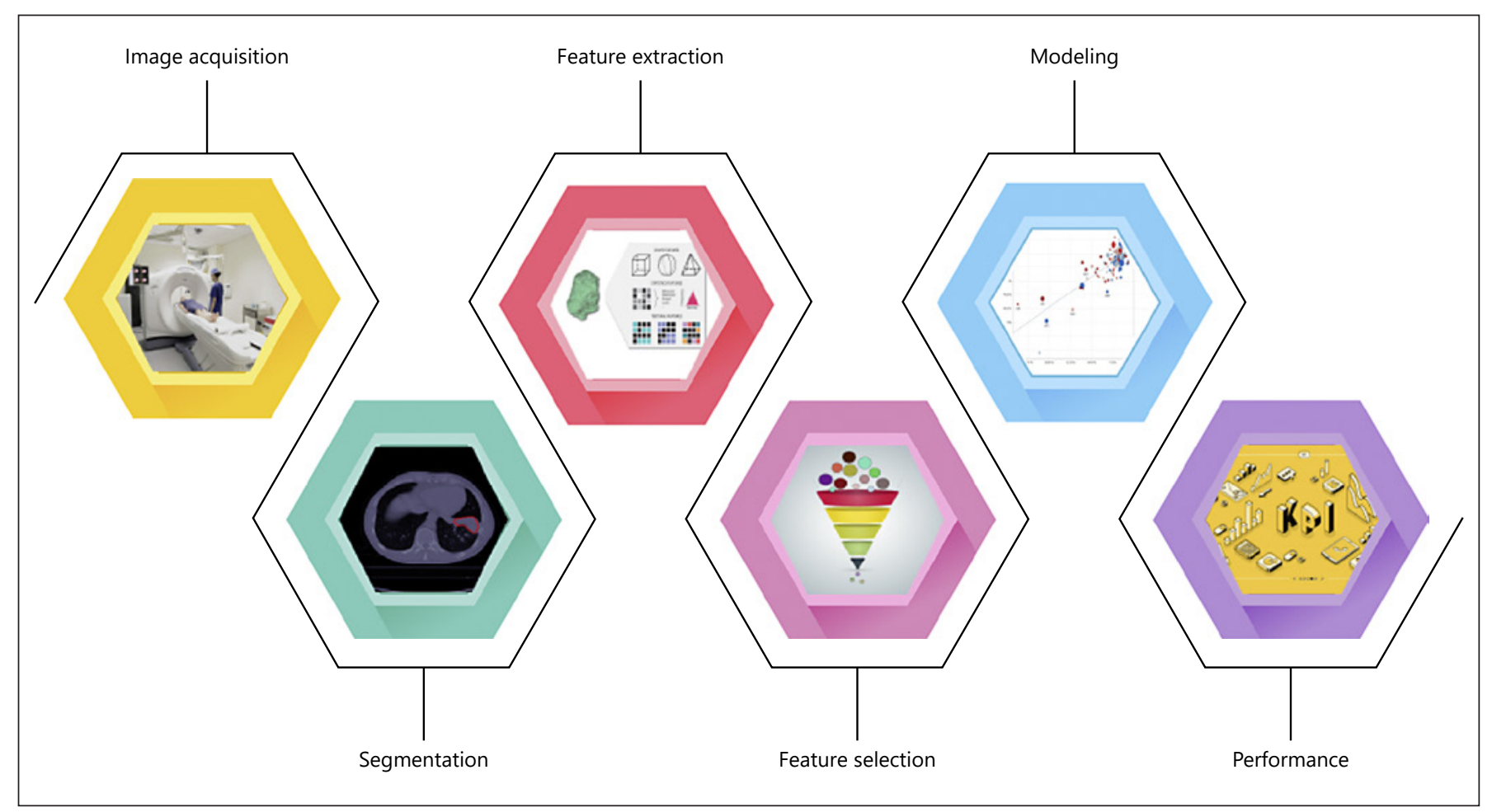

Fig. 2. Graphic depiction of the radiomics workflow.

COPD [24]. The link of pathophysiological mechanisms between COPD and lung cancer is still not well understood (Fig. 1) [25].

The treatment of patients suffering from either disease would be greatly improved by personalized approaches, where patients are treated based on their and their diseases' individual characteristics rather than subpopulation statistics gained from clinical trials. Which role artificial intelligence will play on the path to this paradigm shift towards individualized treatment selection is being extensively investigated [26]. For example, biopsies are used in clinical practice to phenotype the tumor, but the heterogeneous nature of cancer cells limits the biopsy's capacity to fully capture its condition $[27,28]$. Medical imaging, on the other hand, has the potential to noninvasively assess the phenotypic differences of tumors in three dimensions [29] and has recently experienced great advances in the field of artificial intelligence [30, 31]. In particular, radiomics or quantitative image analysis - the high-throughput extraction of quantitative features from medical images and their correlation with diagnostic and prognostic outcomes - has been researched to decode tumor phenotypes from a number of modalities such as CT, magnetic resonance imaging, and positron emission tomography (PET). Thousands of quantitative radiomic features can be extracted from each region of interest (ROI) and further analyzed using machine learning tools to investigate correlations with biological and clinical end points [32-37]. Therefore, the application of radiomics to both COPD and lung cancer may improve the clinical workflow in diagnosing, managing, and following up the patients. It can provide noninvasive, reliable, and costeffective clinical decision support systems, decreasing the need for invasive procedures.

\section{The Workflow of Radiomics}

The process of handcrafted radiomics consists of several steps (Fig. 2): (1) collection of medical imaging (e.g., $\mathrm{CT}$, magnetic resonance, PET/CT) for the target population; (2) segmentation of the ROI to be investigated; (3) extraction of radiomic features from the ROI; (4) the selection of radiomic features that best correlate with the outcome of interest; (5) building the radiomics signature, and (6) evaluation of the model performance on various 
data sets using different metrics such as the receiver-operating characteristic, area under the curve, and the precision-recall curve. The workflow has been previously described in detail $[30,37,38]$.

\section{Quality of Radiomics Studies}

Despite the potential of radiomics to facilitate precision medicine as highlighted in numerous publications, a number of obstacles still limits the generalizability of radiomics signatures, and thus their translation to clinical applications. The most important and widely known limitation is the lack of reproducibility for radiomics biomarkers [39-41]. Several studies have investigated the stability of radiomic features with test-retest experiments [42-44] and reported that a considerable percentage of features is not reproducible in test-retest settings, i.e. using the same acquisition and reconstruction parameters on the same vendor for acquiring the scan. A study by Zhovannic et al. [45] demonstrated that 62 of radiomic features are sensitive to differences in acquisition and reconstruction parameters using the same imaging vendor. Other studies investigated the sensitivity of radiomic features to differences in segmentations, or what is known as interobserver variability [46].

As such, efforts must be made to unify image acquisition and reconstruction across different centers to facilitate quantitative imaging analysis research and integrate these methods into clinical decision support systems.

Several guidelines have been proposed to ensure that radiomic studies are methodologically sound and reproducible. Clear reporting in radiomics research is required to minimize bias and enhance the general application of prediction models. For instance, the Transparent Reporting of a Multivariable Prediction Model for Individual Prognosis or Diagnosis (TRIPOD) initiative has established several recommendations in terms of reporting of the methodology of prediction models [47]. The Radiomics Quality Score is, however, established specifically for radiomics research [38]; it is a checklist that contains 16 elements to evaluate the design and reporting of a radiomics study. The Radiomics Quality Score guidelines include robust segmentation, the stability of testretest, description of imaging protocol used, and internal/ external validation. Due to the fast pace of advancement in this field, further improvement in the standardization of this score is required to ensure a high-quality workflow. Furthermore, the Image Biomarker Standardization Initiative (IBSI) is a newly formed guideline to address the standardization of feature calculation and image preprocessing [48].

\section{Role of Radiomics in Lung Cancer}

\section{Diagnosis}

Several studies have explored the use of radiomics in the screening of lung cancer. The advent of low-dose CT (LDCT) has altered the landscape of lung cancer screening. Studies indicate that LDCT imaging, unlike molecular markers in blood, sputum, and bronchial brushings, detects many tumors at early stages. For instance, the National Lung Screening Trial (NLST) in the USA demonstrated in a large population of 53,454 participants at a high risk for lung cancer a $20 \%$ relative reduction in mortality when participants underwent three annual screening (LDCT) scans instead of singleview posterior-anterior chest radiography [49]. Kumar et al. [50] used a LIDC-IDRI data set in order to differentiate between benign and malignant lesions, resulting in sensitivity and specificity of 79.06 and $76.11 \%$, respectively. Other publications have already shown promising results in the diagnosis of lung cancer [5153].

\section{Staging}

Tumor/node/metastasis (TNM) staging of lung cancer is also important for cancer treatment. Several studies showed the added value of radiomic features in lung cancer staging. A study by Aerts et al. [54] that included 1,019 patients to extract $440 \mathrm{CT}$ radiomics per patient reported that radiomic features were associated with the overall stage (TNM) of lung cancer. A study by Wu et al. [55] that used radiomic characteristics extracted from PET/CT to predict the early stage of distant metastasis (DM) in 101 early-stage NSCLC patients showed that PET radiomic features correlated with DM and had added value in $\mathrm{M}$ staging. Coroller et al. [35] applied radiomics on 182 lung adenocarcinomas in order to predict DM showing that radiomics performed well on $\mathrm{M}$ staging.

\section{Genetics and Histopathology}

Besides diagnosing and staging lung cancer, the use of radiomics has been extended to predict gene mutation or different pathology types of lung cancer. A study by Zhang et al. [56] that included 298 patients found a correlation between epidermal growth factor receptor mutation and CT radiomics features. Liu et al. [57, 58] achieved the same results. Rios Velasquez et al. [59] developed a radiomic model that classifies mutations in patients with lung adenocarcinoma. The research found that the radiomic signature based on CT images can predict epidermal growth factor receptor status effectively. Wu et al. 
[52] used two NSCLC cohorts from the Netherlands to predict the histological types of lung cancer (adenocarcinoma, squamous cell carcinoma).

\section{Response to Therapy}

The use of radiomics signatures could be used to predict the response of patients to a particular therapy. In a study by Aerts et al. [60], it was reported that radiomics features obtained from CT images before treatment were able to predict the mutation status of epidermal growth factor receptor in NSCLC and correlated with gefitinib response. Coroller et al. [61] showed that radiomic features-based CT images acquired prior to treatment could predict the pathological response to chemoradiation in NSCLC patients. Mattonen et al. $[62,63]$ predicted the recurrence of lung cancer following receiving stereotactic ablative radiation therapy using radiomics. Another study that utilized $\delta$-radiomics, a method of analyzing the difference of radiomic features obtained from longitudinal scans, in stage III NSCLC patients to predict the outcome during radiation therapy, reported that the change in radiomic features values might be linked to the tumor response due to exposure to radiation [64]. Hao et al. [65] used radiomic characteristics of peritumoral tissue derived from PET images to study its correlation with distant failure in NSCLC and cervical cancer. The results showed a relationship between tumor boundaries and distant failure, suggesting that such an approach might be useful in predicting early response to radiotherapy in NSCLC and cervical cancer patients. In a recent study by Khorramin et al. [66], CT-based radiomic features were extracted from peri- and intratumoral lung adenocarcinoma tissue and shown to have the potential to predict the response to chemotherapy, and this correlated with both time to progression and overall survival for patients with NSCLC.

\section{Prognosis}

Several studies investigated the prognosis of lung cancer using a radiomics approach. Coroller et al. [35] found a prognostic relation between radiomics features and DM and survival in patients with lung cancer. Aerts et al. [54] found an association between the prognosis of lung cancer and radiomics features. Balagurunathan et al. [42] showed a correlation between the prognosis of lung cancer and radiomic features. Song et al. [67] showed a connection between features extracted from CT images and overall survival in NSCLC patients.

\section{Potential Translation of Radiomics in COPD}

The heterogeneous nature of COPD makes diagnosis challenging. However, it is crucial to unravel this variety of presentations to achieve an accurate diagnosis in early stages and help improve patients' outcomes [5]. Different COPD assessments are used in clinical practice, including pulmonary function test and quantitative CT (QCT). Pulmonary function tests are essential to diagnose and classify COPD. A commonly used pulmonary function test is spirometry, which is used to measure the forced expiratory volume in $1 \mathrm{~s}$ (FEV1) and the forced vital capacity (FVC) as the primary parameters [68]. However, spirometry alone does not provide any locational information regarding emphysema [68]. QCT is a promising approach that is able to quantify emphysema, airways abnormalities, and air trapping [5]. QCT has already demonstrated the capacity to evaluate the existence and degree of emphysema [69-75]. For example, CT densitometry parameters such as relative low-attenuation area [76-81] and percentile of the frequency-attenuation distribution [9, 82-84] are usually used to assess the degree of emphysema. Airways abnormalities are commonly measured by the calculation of the square root at an internal perimeter of $10 \mathrm{~mm}$ using linear regression [85-88]. It is considered the gold standard tool and has already demonstrated a significant correlation with the histological measurement of small airways [89]. Air trapping appears as decreased attenuation on expiratory CT images [90], making it the best way to evaluate air trapping in COPD [87]. The measurements of gas trapping using CT are highly correlated with pulmonary function tests in COPD patients [91].

Despite the ability of QCT to quantify COPD, the interpretation of QCT is still time-consuming, qualitative, requires experts, and is prone to variability in the diagnosis between experts. The CT image metric (radiomics) approach could potentially quantify COPD and uncover the disease's hidden mechanism and the link between lung cancer and COPD in a better nuanced and more powerful phenotypic classification. A radiomics signature would be easier to apply as a clinical decision support system and less time consuming compared to the currently used QCT. Therefore, several potential applications for radiomic features in COPD are suggested. Texture analysis for example has shown its effectiveness in assessing the degree of emphysema. A study by Ginsburg et al. [92] demonstrated the effectiveness of a texture-based approach in classifying between the lungs of never-smokers, smokers without emphysema, and smokers with emphysema, indicating that an early stage of smoking-related 
lung injury could potentially be identified before emphysema develops. Another study by Castadi et al. [93] used a local histogram-based technique to quantify the distinct emphysema pattern using CT scans from 9,313 smoker subjects in the COPODGene study. The results of the study suggest that information extracted from CT patterns of emphysema were more predictive than threshold-based emphysema measurements such as "low attenuation area less than -950". As described above, the applications of radiomics in the screening of lung cancer showed interesting results. Automated screening of routine chest $\mathrm{CT}$ to diagnose COPD is therefore one possible use, with the ability to detect suspected sarcopenia not only in the lung, but also in the muscle tissue. Detection and differentiation between COPD stages and phenotypes, especially in early stages, will allow for the early and suitable treatment for the patient. In a study by Lafata et al. [94], the authors reported on the potential of radiomic features extracted from CT images to quantify the changes in lung function and associated with a spirometry test. The same approach using radiomics could be extended to investigate its relationship with other gold standard COPD markers such as waking exams, FEV/FVC ratio (Tiffeneau index) or the frequency of exacerbations associated with COPD patients, enabling an accurate diagnosis of COPD severity. In addition, the use of radiomics could improve the performance of the existing multifactorial models (nomograms) by adding radiomics features to existing clinical factors (age, sex, number of packyears, current smoking, performance score, wheezing) as already shown in a previous publication [95]. $\delta$-radiomics has already demonstrated its ability to predict the response to therapy in lung cancer. Therefore, such a technique could be used to identify quantitatively the evolution of the disease and the effect of (new) treatment. Additionally, $\delta$-radiomics could be applied to assess the difference between inspiration and expiration scans and to explore hidden information that could help in evaluating the extent and severity of pulmonary emphysema, air trapping, and airway abnormalities. The use of radiomics could potentially be used to predict whether the patient will respond to certain interventions, such as endoscopic lung volume reduction and inhalation steroids.

\section{Conclusion}

The field of radiomics is rapidly growing and has already shown its potential in assessing lung cancers in terms of detection, treatment response, and prognosis.
Different QCT measurements have been used to quantify COPD abnormalities such as emphysema, air trapping, and airway remodeling. Applying radiomics in COPD has not been extensively investigated yet. We show examples of the potential use of radiomics in the diagnosis, treatment, and the follow-up of COPD and future directions for further research.

\section{Acknowledgments}

The authors acknowledge financial support from ERC advanced grant (ERC-ADG-2015, No. 694812 - Hypoximmuno) and ERC-2018-PoC (No. 81320-CL-IO). This research is also supported by the Dutch Technology Foundation STW (grant No. P14-19 Radiomics STRaTegy), which is the applied science division of NWO, and the Technology Programme of the Ministry of Economic Affairs. The authors also acknowledge financial support from SME Phase 2 (RAIL - No. 673780), EUROSTARS (DART, DECIDE), PREDICT (ITN - No. 766276), TRANSCAN Joint Transnational Call 2016 (JTC2016 "CLEARLY" - No. UM 20178295), Interreg V-A Euregio Meuse-Rhine ("Euradiomics"), Kankeronderzoekfonds Limburg (KOFL) from the Health Foundation Limburg, and the Dutch Cancer Society.

\section{Disclosure Statement}

Dr. Philippe Lambin reports, within and outside the submitted work, grants/sponsored research agreements from Varian medical, Oncoradiomics, ptTheragnostic and Health Innovation Ventures. He received an advisor/presenter fee and/or reimbursement of travel costs/external grant writing fee and/or in kind manpower contribution from Oncoradiomics, BHV, Merck, Varian, Elekta and Convert pharmaceuticals. Dr. Lambin has (minority) shares in the company Oncoradiomics SA and Convert pharmaceuticals SA and is co-inventor of two issued patents with royalties on radiomics (PCT/NL2014/050248, PCT/NL2014/050728) licensed to Oncoradiomics and one issue patent on mtDNA (PCT/ EP2014/059089) licensed to ptTheragnostic/DNAmito, three nonpatentable invention (softwares) licensed to ptTheragnostic/ DNAmito, Oncoradiomics and Health Innovation Ventures. Dr. Woodruff and Dr. Leijenaar have (minority) shares in the company Oncoradiomics.

\section{References}

1 Quaderi S, Hurst J. The unmet global burden of COPD. Global Health Epidemiol Genom. 2018;3:e4.https://doi.org/10.1017/gheg.2018.1.

2 Rabe KF, Hurd S, Anzueto A, Barnes PJ, Buist SA, Calverley P, et al.; Global Initiative for Chronic Obstructive Lung Disease. Global strategy for the diagnosis, management, and prevention of chronic obstructive pulmonary disease: GOLD executive summary. Am J Respir Crit Care Med. 2007 Sep;176(6):532-55. 
3 Celli BR, MacNee W, Agusti A, Anzueto A, Berg B, Buist AS, et al.; ATS/ERS Task Force. Standards for the diagnosis and treatment of patients with COPD: a summary of the ATS/ ERS position paper. Eur Respir J. 2004 Jun; 23(6):932-46.

4 Vogelmeier CF, Criner GJ, Martinez FJ, Anzueto A, Barnes PJ, Bourbeau J, et al. Global Strategy for the Diagnosis, Management, and Prevention of Chronic Obstructive Lung Disease 2017 Report. GOLD Executive Summary. Am J Respir Crit Care Med. 2017 Mar; 195(5):557-82.

5 Mets OM, de Jong PA, van Ginneken B, Gietema HA, Lammers JW. Quantitative computed tomography in COPD: possibilities and limitations. Lung. 2012 Apr;190(2):133-45.

6 Bodduluri S, Reinhardt JM, Hoffman EA, Newell JD Jr, Bhatt SP. Recent Advances in Computed Tomography Imaging in Chronic Obstructive Pulmonary Disease. Ann Am Thorac Soc. 2018 Mar; 15(3):281-9.

7 Müller NL, Staples CA, Miller RR, Abboud RT. "Density mask". An objective method to quantitate emphysema using computed tomography. Chest. 1988 Oct;94(4):782-7.

8 Gevenois PA, de Maertelaer V, De Vuyst P, Zanen J, Yernault JC. Comparison of computed density and macroscopic morphometry in pulmonary emphysema. Am J Respir Crit Care Med. 1995 Aug;152(2):653-7.

9 Madani A, Zanen J, de Maertelaer V, Gevenois PA. Pulmonary emphysema: objective quantification at multi-detector row CTcomparison with macroscopic and microscopic morphometry. Radiology. 2006 Mar; 238(3):1036-43.

10 Gietema HA, Schilham AM, van Ginneken B, van Klaveren RJ, Lammers JW, Prokop M. Monitoring of smoking-induced emphysema with CT in a lung cancer screening setting: detection of real increase in extent of emphysema. Radiology. 2007 Sep;244(3):890-7.

11 de Jong PA, Müller NL, Paré PD, Coxson HO. Computed tomographic imaging of the airways: relationship to structure and function. Eur Respir J. 2005 Jul;26(1):140-52.

12 Mets OM, Zanen P, Lammers JW, Isgum I, Gietema HA, van Ginneken B, et al. Early identification of small airways disease on lung cancer screening CT: comparison of current air trapping measures. Lung. 2012 Dec; 190(6):629-33

13 Fabre Ballalai Ferraz A, Rosim R, Anaya P. Standardization process of raw data and consumption analysis of oncology therapies in the Brazil public health care system: a comparison between raw and standardized dataset in colorectal and lung cancer. Value Health. 2015;18:A811. https://doi.org/ 10.1016/j.jval.2015.09.107.

14 Faris N, Yu X, Sareen S, Signore RS, McHugh LM, Roark K, et al. Preoperative Evaluation of Lung Cancer in a Community Health Care Setting. Ann Thorac Surg. 2015 Aug; 100(2): 394-400.
15 Ryoo JJ, Malin JL, Ordin DL, Oishi SM, Kim B, Asch SM, et al. Facility characteristics and quality of lung cancer care in an integrated health care system. J Thorac Oncol. 2014 Apr; 9(4):447-55.

16 Sundaram B, Kazerooni EA. Preface. Lung cancer is an important public health care issue. Radiol Clin North Am. 2012 Sep;50(5):xi.

17 Bray F, Ferlay J, Soerjomataram I, Siegel RL, Torre LA, Jemal A. Global cancer statistics 2018: GLOBOCAN estimates of incidence and mortality worldwide for 36 cancers in 185 countries. CA Cancer J Clin. 2018 Nov;68(6): 394-424.

18 Palma JF, Das P, Liesenfeld O. Lung cancer screening: utility of molecular applications in conjunction with low-dose computed tomography guidelines. Expert Rev Mol Diagn. 2016;16(4):435-47.

19 Long F, Su J-H, Liang B, et al. Identification of gene biomarkers for distinguishing small-cell lung cancer from non-small-cell lung cancer using a network-based approach. Biomed Res Int. 2015;2015:685303. https://doi.org/ $10.1155 / 2015 / 685303$.

20 Durham AL, Adcock IM. The relationship between COPD and lung cancer. Lung Cancer. 2015 Nov;90(2):121-7.

21 Raviv S, Hawkins KA, DeCamp MM Jr, Kalhan R. Lung cancer in chronic obstructive pulmonary disease: enhancing surgical options and outcomes. Am J Respir Crit Care Med. 2011 May;183(9):1138-46.

22 Houghton AM. Mechanistic links between COPD and lung cancer. Nat Rev Cancer. 2013 Apr;13(4):233-45.

23 Eapen MS, Hansbro PM, Larsson-Callerfelt AK, Jolly MK, Myers S, Sharma P, et al. Chronic obstructive pulmonary disease and lung cancer: underlying pathophysiology and new therapeutic modalities. Drugs. 2018 Nov; 78(16):1717-40.

24 Wang P, Zhu M, Zhang D, Guo XG, Zhao S, Zhang XL, et al. The relationship between chronic obstructive pulmonary disease and non-small cell lung cancer in the elderly. Cancer Med. 2019 Aug;8(9):4124-34.

25 Chalela R, Gea J, Barreiro E. Immune phenotypes in lung cancer patients with COPD: potential implications for immunotherapy. J Thorac Dis. 2018 Jul;10(S18 Suppl 18):S2186-9.

26 Jackson SE, Chester JD. Personalised cancer medicine. Int J Cancer. 2015 Jul;137(2):2626.

27 Gerlinger M, Rowan AJ, Horswell S, Math M, Larkin J, Endesfelder D, et al. Intratumor heterogeneity and branched evolution revealed by multiregion sequencing. $\mathrm{N}$ Engl J Med. 2012 Mar;366(10):883-92.

28 Gerlinger M, Swanton C. How Darwinian models inform therapeutic failure initiated by clonal heterogeneity in cancer medicine. Br J Cancer. 2010 Oct;103(8):1139-43.

29 Gillies RJ, Kinahan PE, Hricak H. Radiomics: images are more than pictures, they are data. Radiology. 2016 Feb;278(2):563-77.
30 Ibrahim A, Vallières $\mathrm{M}$, Woodruff $\mathrm{H}$, et al Radiomics analysis for clinical decision support in nuclear medicine. Semin Nucl Med. 2019;49(5):438-49. https://doi.org/10.1053/j. semnuclmed.2019.06.005.

31 Walsh S, de Jong EE, van Timmeren JE, et al. Decision support systems in oncology. JCO Clin Cancer Informat. 2019;3:1-9. https:// doi.org/10.1200/CCI.18.00001.

32 Carvalho S, Leijenaar RT, Velazquez ER, Oberije C, Parmar C, van Elmpt W, et al Prognostic value of metabolic metrics extracted from baseline positron emission tomography images in non-small cell lung cancer Acta Oncol. 2013 Oct:52(7):1398-404.

33 Cook GJ, O’Brien ME, Siddique M, Chicklore S, Loi HY, Sharma B, et al. Non-Small Cell Lung Cancer Treated with Erlotinib: Heterogeneity of (18)F-FDG Uptake at PET-Association with Treatment Response and Prognosis. Radiology. 2015 Sep;276(3):883-93.

34 Cook GJ, Yip C, Siddique M, Goh V, Chicklore S, Roy A, et al. Are pretreatment $18 \mathrm{~F}$ FDG PET tumor textural features in nonsmall cell lung cancer associated with response and survival after chemoradiotherapy? J Nucl Med. 2013 Jan;54(1):19-26.

35 Coroller TP, Grossmann P, Hou Y, Rios Velazquez E, Leijenaar RT, Hermann G, et al. CT-based radiomic signature predicts distant metastasis in lung adenocarcinoma. Radiother Oncol. 2015 Mar;114(3):345-50.

36 Fried DV, Tucker SL, Zhou S, Liao Z, Mawlawi O, Ibbott G, et al. Prognostic value and reproducibility of pretreatment CT texture features in stage III non-small cell lung cancer. Int J Radiat Oncol Biol Phys. 2014 Nov; 90(4):834-42.

37 Lambin P, Rios-Velazquez E, Leijenaar R, Carvalho S, van Stiphout RG, Granton P, et al Radiomics: extracting more information from medical images using advanced feature analysis. Eur J Cancer. 2012 Mar;48(4):441-6.

38 Lambin P, Leijenaar RT, Deist TM, Peerlings J, de Jong EE, van Timmeren J, et al. Radiomics: the bridge between medical imaging and personalized medicine. Nat Rev Clin Oncol. 2017 Dec;14(12):749-62.

39 Leijenaar RT, Nalbantov G, Carvalho S, van Elmpt WJ, Troost EG, Boellaard R, et al. The effect of SUV discretization in quantitative FDG-PET Radiomics: the need for standardized methodology in tumor texture analysis. Sci Rep. 2015 Aug;5(1):11075.

40 Van Velden FH, Kramer GM, Frings V, Nissen IA, Mulder ER, de Langen AJ, et al. Repeatability of radiomic features in non-smallcell lung cancer [18F]FDG-PET/CT studies: impact of reconstruction and delineation. Mol Imaging Biol. 2016 Oct;18(5):788-95.

41 Zhao B, Tan Y, Tsai WY, Qi J, Xie C, Lu L, et al. Reproducibility of radiomics for deciphering tumor phenotype with imaging. Sci Rep. 2016 Mar;6(1):23428. 
42 Balagurunathan $\mathrm{Y}, \mathrm{Gu} \mathrm{Y}$, Wang H, Kumar V, Grove O, Hawkins S, et al. Reproducibility and prognosis of quantitative features extracted from CT images. Transl Oncol. 2014 Feb;7(1):72-87.

43 Balagurunathan Y, Kumar V, Gu Y, Kim J, Wang H, Liu Y, et al. Test-retest reproducibility analysis of lung CT image features. J Digit Imaging. 2014 Dec;27(6):805-23.

44 Tixier F, Hatt M, Le Rest CC, Le Pogam A, Corcos L, Visvikis D. Reproducibility of tumor uptake heterogeneity characterization through textural feature analysis in 18F-FDG PET. J Nucl Med. 2012 May;53(5):693-700.

45 Zhovannik I, Bussink J, Traverso A, et al. Learning from scanners: bias reduction and feature correction in radiomics. Clin Transl Radiat Oncol. 2019;19:33-38.

46 Yip SS, Aerts HJ. Applications and limitations of radiomics. Phys Med Biol. 2016 Jul; 61(13):R150-66.

47 Collins GS, Reitsma JB, Altman DG, Moons KG. Transparent Reporting of a multivariable prediction model for Individual Prognosis or Diagnosis (TRIPOD): the TRIPOD statement. Ann Intern Med. 2015 Jan;162(1):55-63.

48 Zwanenburg A, Leger S, Vallières M, et al. Image biomarker standardisation initiative. arXiv preprint, Cornell University. 2016;arXiv: 161207003.

49 Aberle DR, Adams AM, Berg CD, Black WC, Clapp JD, Fagerstrom RM, et al.; National Lung Screening Trial Research Team. Reduced lung-cancer mortality with low-dose computed tomographic screening. N Engl J Med. 2011 Aug;365(5):395-409.

50 Kumar D, Shafiee MJ, G. Chung A, et al: Discovery Radiomics for Computed Tomography Cancer Detection. 2015

51 Liu Y, Balagurunathan Y, Atwater T, Antic S, Li Q, Walker RC, et al. Radiological Image Traits Predictive of Cancer Status in Pulmonary Nodules. Clin Cancer Res. 2017 Mar; 23(6):1442-9.

52 Wu W, Parmar C, Grossmann P, Quackenbush J, Lambin P, Bussink J, et al. Exploratory study to identify radiomics classifiers for lung cancer histology. Front Oncol. 2016 Mar;6:71.

53 Maldonado F, Boland JM, Raghunath S, Aubry MC, Bartholmai BJ, Deandrade M, et al. Noninvasive characterization of the histopathologic features of pulmonary nodules of the lung adenocarcinoma spectrum using computer-aided nodule assessment and risk yield (CANARY) - a pilot study. J Thorac Oncol. 2013 Apr;8(4):452-60.

54 Aerts HJ, Velazquez ER, Leijenaar RT, Parmar C, Grossmann P, Carvalho S, et al. Decoding tumour phenotype by noninvasive imaging using a quantitative radiomics approach. Nat Commun. 2014 Jun;5(1):4006.

55 Wu J, Aguilera T, Shultz D, Gudur M, Rubin DL, Loo BW Jr, et al. Early-stage non-small cell lung cancer: quantitative imaging characteristics of $18 \mathrm{~F}$ fluorodeoxyglucose PET/CT allow prediction of distant metastasis. Radiology. 2016 Oct;281(1):270-8.
56 Zhang L, Chen B, Liu X, Song J, Fang M, Hu C, et al. Quantitative biomarkers for prediction of epidermal growth factor receptor mutation in non-small cell lung Cancer. Transl Oncol. 2018 Feb;11(1):94-101.

57 Liu Y, Kim J, Balagurunathan Y, Li Q, Garcia AL, Stringfield O, et al. Radiomic Features Are Associated With EGFR Mutation Status in Lung Adenocarcinomas. Clin Lung Cancer. 2016 Sep;17(5):441-448.e6.

58 Liu Y, Kim J, Qu F, Liu S, Wang H, Balagurunathan $\mathrm{Y}$, et al. CT features associated with epidermal growth factor receptor mutation status in patients with lung adenocarcinoma. Radiology. 2016 Jul;280(1):271-80.

59 Rios Velazquez E, Parmar C, Liu Y, Coroller TP, Cruz G, Stringfield O, et al. Somatic Mutations Drive Distinct Imaging Phenotypes in Lung Cancer. Cancer Res. 2017 Jul;77(14): 3922-30.

60 Aerts HJ, Grossmann P, Tan Y, Oxnard GR, Rizvi N, Schwartz LH, et al. Defining a radiomic response phenotype: a pilot study using targeted therapy in NSCLC. Sci Rep. 2016 Sep;6(1):33860.

61 Coroller TP, Agrawal V, Narayan V, Hou Y, Grossmann P, Lee SW, et al. Radiomic phenotype features predict pathological response in non-small cell lung cancer. Radiother Oncol. 2016 Jun;119(3):480-6.

62 Mattonen S, Tetar S, Palma D, et al. Automated texture analysis for prediction of recurrence after stereotactic ablative radiation therapy for lung cancer. Int J Radiat Oncol Biol Phys. 2015;93:S5-S6. https://doi.org/ 10.1016/j.ijrobp.2015.07.019

63 Mattonen SA, Palma DA, Haasbeek CJ, Senan $S$, Ward AD. Early prediction of tumor recurrence based on CT texture changes after stereotactic ablative radiotherapy (SABR) for lung cancer. Med Phys. 2014 Mar;41(3): 033502.

64 Fave X, Zhang L, Yang J, Mackin D, Balter P, Gomez D, et al. Delta-radiomics features for the prediction of patient outcomes in nonsmall cell lung cancer. Sci Rep. 2017 Apr;7(1): 588.

65 Hao H, Zhou Z, Li S, Maquilan G, Folkert MR, Iyengar $\mathrm{P}$, et al. Shell feature: a new radiomics descriptor for predicting distant failure after radiotherapy in non-small cell lung cancer and cervix cancer. Phys Med Biol. 2018 May; 63(9):095007.

66 Khorrami M, Khunger M, Zagouras A, et al. Combination of peri- and intratumoral radiomic features on baseline CT scans predicts response to chemotherapy in lung adenocarcinoma. Radiol Artif Intell. 2019;1: 180012.

67 Song J, Liu Z, Zhong W, Huang Y, Ma Z, Dong $D$, et al. Non-small cell lung cancer: quantitative phenotypic analysis of CT images as a potential marker of prognosis. Sci Rep. 2016 Dec;6(1):38282

68 Matsuoka S, Yamashiro T, Washko GR, Kurihara Y, Nakajima Y, Hatabu H. Quantitative $\mathrm{CT}$ assessment of chronic obstructive pulmo- nary disease. Radiographics. 2010 Jan;30(1): 55-66.

69 Bergin C, Müller N, Nichols DM, Lillington G, Hogg JC, Mullen B, et al. The diagnosis of emphysema. A computed tomographicpathologic correlation. Am Rev Respir Dis. 1986 Apr;133(4):541-6.

70 Coddington R, Mera SL, Goddard PR, Bradfield JW. Pathological evaluation of computed tomography images of lungs. J Clin Pathol. 1982 May;35(5):536-40.

71 Foster WL Jr, Pratt PC, Roggli VL, Godwin JD, Halvorsen RA Jr, Putman CE. Centrilobular emphysema: CT-pathologic correlation. Radiology. 1986 Apr;159(1):27-32.

72 Goddard PR, Nicholson EM, Laszlo G, Watt I. Computed tomography in pulmonary emphysema. Clin Radiol. 1982 Jul;33(4):379-87.

73 Kreel L: Computed tomography of the thorax. Med Imag. 1979:132-139.

74 Morgan MD, Strickland B. Computed tomography in the assessment of bullous lung disease. Br J Dis Chest. 1984 Jan;78(1):10-25.

75 Rosenblum LJ, Mauceri RA, Wellenstein DE, Bassano DA, Cohen WN, Heitzman ER Computed tomography of the lung. Radiology. 1978 Nov; $129(2): 521-4$.

76 Bankier AA, De Maertelaer V, Keyzer C, Gevenois PA. Pulmonary emphysema: subjective visual grading versus objective quantification with macroscopic morphometry and thin-section CT densitometry. Radiology. 1999 Jun;211(3):851-8.

77 Gevenois PA, De Vuyst P, de Maertelaer V, Zanen J, Jacobovitz D, Cosio MG, et al. Comparison of computed density and microscopic morphometry in pulmonary emphysema. Am J Respir Crit Care Med. 1996 Jul;154(1): 187-92.

78 Gurney JW, Jones KK, Robbins RA, Gossman GL, Nelson KJ, Daughton D, et al. Regional distribution of emphysema: correlation of high-resolution CT with pulmonary function tests in unselected smokers. Radiology. 1992 May;183(2):457-63.

79 Kinsella M, Müller NL, Abboud RT, Morrison NJ, DyBuncio A. Quantitation of emphysema by computed tomography using a "density mask" program and correlation with pulmonary function tests. Chest. $1990 \mathrm{Feb} ; 97(2)$ : $315-21$.

80 Knudson RJ, Standen JR, Kaltenborn WT, Knudson DE, Rehm K, Habib MP, et al. Expiratory computed tomography for assessment of suspected pulmonary emphysema. Chest. 1991 Jun;99(6):1357-66

81 Lucidarme O, Coche E, Cluzel P, MoureyGerosa I, Howarth N, Grenier P. Expiratory CT scans for chronic airway disease: correlation with pulmonary function test results. AJR Am J Roentgenol. 1998 Feb;170(2):3017.

82 Dirksen A, Dijkman JH, Madsen F, Stoel B, Hutchison DC, Ulrik CS, et al. A randomized clinical trial of $\alpha(1)$-antitrypsin augmentation therapy. Am J Respir Crit Care Med. 1999 Nov;160(5 Pt 1):1468-72. 
83 Dirksen A, Friis M, Olesen KP, Skovgaard LT, Sørensen K. Progress of emphysema in severe a 1-antitrypsin deficiency as assessed by annual CT. Acta Radiol. 1997 Sep;38(5):826-32.

84 Gould GA, MacNee W, McLean A, Warren PM, Redpath A, Best JJ, et al. CT measurements of lung density in life can quantitate distal airspace enlargement-an essential defining feature of human emphysema. Am Rev Respir Dis. 1988 Feb;137(2):380-92.

85 Grydeland TB, Dirksen A, Coxson HO, Pillai SG, Sharma S, Eide GE, et al. Quantitative computed tomography: emphysema and airway wall thickness by sex, age and smoking. Eur Respir J. 2009 Oct;34(4):858-65.

86 Patel BD, Coxson HO, Pillai SG, Agustí AG, Calverley PM, Donner CF, et al.; International COPD Genetics Network. Airway wall thickening and emphysema show independent familial aggregation in chronic obstructive pulmonary disease. Am J Respir Crit Care Med. 2008 Sep;178(5):500-5.

87 Smith BM, Hoffman EA, Rabinowitz D, Bleecker E, Christenson S, Couper D, et al.; The Multi-Ethnic Study of Atherosclerosis
(MESA) COPD Study and the Subpopulations and Intermediate Outcomes in COPD Study (SPIROMICS). Comparison of spatially matched airways reveals thinner airway walls in COPD. Thorax. 2014 Nov;69(11): 987-96.

88 Woodruff PG, Couper D, Han MK. Symptoms in Smokers with Preserved Pulmonary Function. N Engl J Med. 2016 Sep;375(9): 896-7.

89 Nakano Y, Wong JC, de Jong PA, Buzatu L, Nagao T, Coxson HO, et al. The prediction of small airway dimensions using computed tomography. Am J Respir Crit Care Med. 2005 Jan;171(2):142-6.

90 Matsuoka S, Kurihara Y, Yagihashi K, Hoshino M, Watanabe N, Nakajima Y. Quantitative assessment of air trapping in chronic obstructive pulmonary disease using inspiratory and expiratory volumetric MDCT. AJR Am J Roentgenol. 2008 Mar;190(3):762-9.

91 Schroeder JD, McKenzie AS, Zach JA, Wilson CG, Curran-Everett D, Stinson DS, et al. Relationships between airflow obstruction and quantitative CT measurements of emphyse- ma, air trapping, and airways in subjects with and without chronic obstructive pulmonary disease. AJR Am J Roentgenol. 2013 Sep; 201(3):W460-70

92 Ginsburg SB, Lynch DA, Bowler RP, Schroeder JD. Automated texture-based quantification of centrilobular nodularity and centrilobular emphysema in chest CT images. Acad Radiol. 2012 Oct;19(10):1241-51.

93 Castaldi PJ, San José Estépar R, Mendoza CS, Hersh CP, Laird N, Crapo JD, et al. Distinct quantitative computed tomography emphysema patterns are associated with physiology and function in smokers. Am J Respir Crit Care Med. 2013 Nov;188(9):1083-90.

94 Lafata KJ, Zhou Z, Liu JG, Hong J, Kelsey CR, Yin FF. An exploratory radiomics approach to quantifying pulmonary function in CT images. Sci Rep. 2019 Aug;9(1):11509.

95 Huang YQ, Liang CH, He L, Tian J, Liang CS, Chen X, et al. Development and Validation of a Radiomics Nomogram for Preoperative Prediction of Lymph Node Metastasis in Colorectal Cancer. J Clin Oncol. 2016 Jun; 34(18):2157-64. 